\title{
ANNUAL MONITORING OF DUST STORM IN IRAN AND ADJACENT AREAS USING MODIS IMAGES (1396 AND 1397 HIJRI SHAMSI)
}

\author{
P. Jafary ${ }^{\text {a, *, A. Zandkarimi }}{ }^{\text {b }}$, M. Jannati ${ }^{\mathrm{c}}$ \\ ${ }^{a}$ GIS Department, Faculty of Geodesy and Geomatics Engineering, K.N. Toosi University of Technology, Tehran, Iran - \\ peyman_jafary_90@yahoo.com \\ ${ }^{\mathrm{b}}$ Department of Remote Sensing and GIS, Tabriz University, Tabriz, Iran - zandkarimi.arash@ gmail.com \\ ${ }^{c}$ Department of remote sensing, IRANIAN SPACE AGENCY (ISA), Tehran, Iran - jannatim1966@ gmail.com
}

KEY WORDS: Dust Storm, MODIS, Cumulative Density, Frequency of Occurrence, Iran

\begin{abstract}
:
The occurrence of dust storms is one of the major problems in Iran and neighboring countries. Monitoring dust storms and identifying their patterns, areas with high frequency of occurrence and high dense storms using remote sensing technology can help decision makers in different dimensions. This paper tries to investigate the occurrence of dust storms in Iran and adjacent regions over two annual periods, and produce the maps of cumulative density and frequency of occurrence in order to find dust patterns and hotspots and make a comparison between these periods. The daily MODIS images received at the Mahdasht Space Center in 1396 and 1397 were used. Brightness temperature images were prepared using these data and the bands 20, 29, 31 and 32 of them were used. After applying appropriate algorithms, daily dust storm maps were produced. Using the data of 212 synoptic stations throughout the country, the accuracy of the algorithms were assessed and the thresholds were modified. By combining these daily maps, annual cumulative density maps were prepared. Also, by combining daily occurrence maps of dust storms, frequency of occurrence maps were produced. The results show that in 1397, more areas have experienced dust storms in comparison to 1396. Besides, the number and density of dust storms at west and southwest areas have been reduced in 1397. Conversely, in the eastern and southeast areas we have faced with an increase in the number and density of monitored dust storms in 1397 . It can be concluded that the problem of dust storms in Iran have been shifted from the west and southwest of the country to the eastern and southeastern regions.
\end{abstract}

\section{INTRODUCTION}

Dust storms are one of the phenomena that occur in arid and semi-arid regions of the world (Heidarian, 2018). Dust storms pose serious problems in human activities, agriculture, social infrastructure, transport, health, and the economy of the community. In addition, the large amount of particles transported to the atmosphere is associated with negative impacts on the climate (Takemi and Seino, 2005). For example, in a study carried out in Zabul, Iran, the damages of the dust storms to the population were estimated at over 66.7 million dollars during 1999-2004 (Miri, 2007).

Every year, large amounts of dust are produced in arid areas and deserts of the world, and the wind extends them thousands of miles away from their production centers (Givehchi, 2013). In recent years, many dust storms have occurred in the Middle East (Taheri Shahraiyni, 2014). Due to the proximity to the three major sources of dust production (the deserts of Iraq, Syria and Saudi Arabia) in the west, "wind of 120 days" common in eastern Iran and western Afghanistan over desert lands as well as drought and inappropriate productivity of land, Iran always encounter dust storms and the resulting problems (Alizadeh, 2014 \& Namdari, 2016). Therefore, it is important to identify and investigate the characteristics of this destructive environmental phenomenon in Iran.

Because of rapid changes in the nature and spatial extension of dust storms, there are different limitations in dust storm monitoring and related measurements (Taheri Shahraiyni, 2014). Nowadays, remote sensing technology by providing multiple global and regional images with different temporal and spatial resolutions is known as a powerful tool for monitoring, measuring and analyzing dust properties (Klüser, 2009 \& Baddock, 2009).

The purpose of the use of satellite images in dust monitoring is to identify pixels that the reflectivity, absorption and distribution of them in different wavelengths have been affected due to the presence of dust particles. So, dust storm is a complex process that affects the interactions between Earth and the atmosphere (Mei, 2008).

In recent years, various studies have been carried out on dust detection and monitoring using remote sensing technology (Mei, 2008; Baddock, 2009; Zhao, 2010; Maghrabi, 2011; Karimi, 2012; Prachi, 2014; Namdari, 2016; Solomos, 2017 \& Kalpoma, 2018). In general, these studies have investigated this phenomenon at smaller areas and have more used thermal infrared bands of satellite images. Also, these studies have less focused on the changes in thresholds in different seasons. Most importantly, the point that has been less addressed in these studies is the investigation of dust storms over long periods of time to detect trends in dust, hotspots, and critical areas where dust phenomena occur with high repeat rates.

According to the World Meteorological Organization standards, dust events are classified into four categories based on the horizontal visibility (Shao, 2006):

1- Dust-in-suspension: horizontal visibility less than 10 $\mathrm{km}$.

2- Blowing dust: horizontal visibility between 1 and 10 $\mathrm{km}$.

\footnotetext{
* Corresponding author
} 
3- Dust storm: horizontal visibility between 200 meters and $1 \mathrm{~km}$.

4- Severe dust Storm: horizontal visibility less than 200 meters.

In this research, the classes 3 and 4 (dust storm and severe dust storm), i.e. horizontal visibility less than $1 \mathrm{~km}$ were considered as dust storm.

This paper therefore aims to investigate the occurrence of dust storms in Iran and neighboring regions over two annual periods, and produce the maps of cumulative density and frequency of occurrence for these two periods in order to find dust patterns and hotspots and make a comparison between these periods.

\section{STUDY AREA AND DATA USED}

\subsection{Study Area}

The study area includes Iran and its adjacent areas (Figure 1). Most of these areas are considered as dry and semi-arid regions. The presence of large arid areas and deserts, soil erosion and formation of soil particles, lack of proper management, the presence of 120 days of winds in the eastern regions, and other natural and human factors create multiple dust storms in the area (Bartlett, $2004 \&$ Taheri Shahraiyni, 2014).

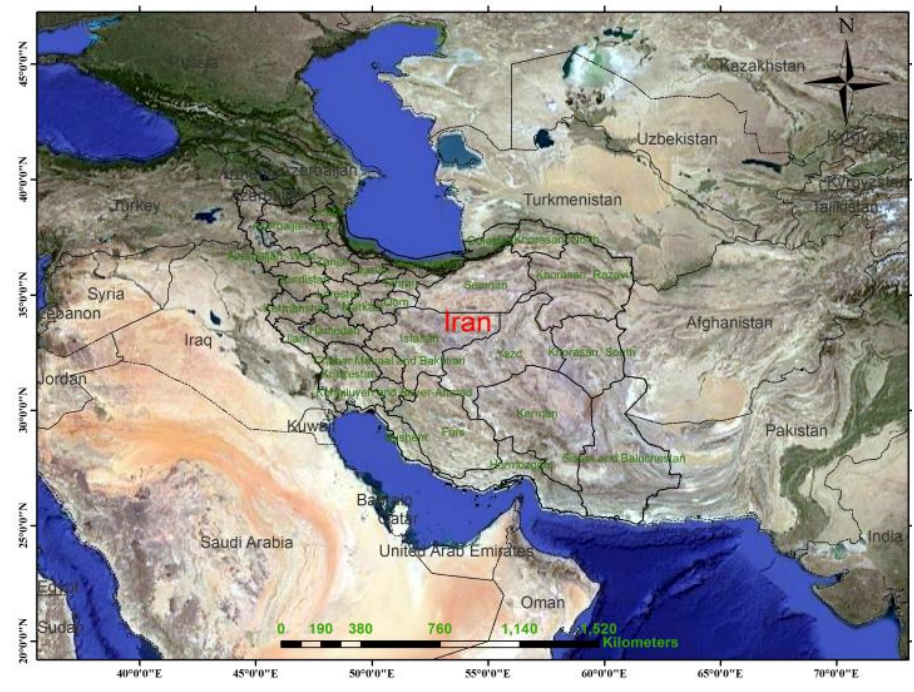

Figure 1. Study area

\subsection{Data Used}

MODIS has been launched onboard the Terra and Aqua satellites which were launched in 1999 and 2002, respectively. MODIS images are presented in 36 bands from visible to infrared ( 0.41 to 14 micrometers) bandwidths. Nominal (at nadir view) spatial resolution is $0.25 \mathrm{~km}$ for two bands $(0.65$ and $0.86 \mu \mathrm{m}), 0.5 \mathrm{~km}$ for five bands $(0.47,0.55,1.24,1.63$ and $2.11 \mu \mathrm{m})$ and $1 \mathrm{~km}$ for the remainder. Terra has a 10:30 and Aqua has a 13:30 local equator crossing time (Levy, 2018). MODIS images are daily received from both satellites at Mahdasht Space Center of Iranian Space Agency. In this study, the level 0 images of this center were used.

\section{METHODOLOGY}

\subsection{Pre-processing MODIS Images}

The MODIS images are received at the Mahdasht Space Center from Terra and Aqua satellite are raw (level 0) and are in PDS format. Therefore, to use these data, three operations must be performed on them: unpacking, geolocation and calibration. Subsequently, $1 \mathrm{~km}$ images (level 2) produced after calibration process must be georeferenced. Finally, after applying the required radiometric and atmospheric corrections, the images are ready to produce dust maps.

\subsection{Processing MODIS Images}

In this stage, brightness temperature images are produced from MODIS images. For the production of dust storm maps in 6 warm months of the year, three layers are used: Band 32, difference between band 20 and band 31 and difference between band 31 and band 32. Also, in the cool 6 months of the year, in addition to these three layers, the difference layer between the 29 and 31 bands is also used. The reason for this is to separate dust storm from desert areas in the cold days of the year. After setting the thresholds for the warm 6 months and cool 6th months of the year, the most appropriate thresholds were determined. After applying the thresholds to the layers and combining them, it is possible to get dust storm maps from MODIS images.

It should be noted that the thresholds have been determined for land area, nor aquatic area. So, this study tries to detect dust storms which have been occurred on the land.

\subsection{Accuracy assessment and improving thresholds}

In this stage, the data of 212 synoptic stations (horizontal visibility and code 06) throughout the country was used. Due to lack of accessibility to the data of adjacent countries, we could not use the data outside the frontier of Iran. The time of collecting this data is almost equal to the crossing time of the satellites. After preparing dust storm maps from MODIS images, the pixels with dust were compared to this data in order to assess the accuracy of the used method and improving the thresholds.

\subsection{Cumulative density map of dust storms}

As previously mentioned, the purpose of this study is to identify and analyze critical areas in terms of dust storm in study area. One way of analyzing critical areas is to combine daily dust storm maps with each other over a year. By this way, it is possible to create annual cumulative density map of dust storms. Areas with higher dust concentrations can be identified using such a map.

\subsection{Frequency of occurrence map of dust storms}

One of the products that can be created based on daily dust storm maps is a map that specifies the pixels that have been in the dusty areas. For preparing such map, for every daily map of dust storms, the value 1 is assigned to the pixels which are in the dusty areas. On the other hand, value 0 is attributed to the rest pixels of the image (without dust). Accordingly, daily occurrence maps of dust storms could be produced. If these created daily maps be combined, an annual frequency of occurrence map of dust storms can be made. Using this map, areas that have the highest number of dust events in a year can accurately identified.

The flowchart of the proposed methodology is presented in Figure 2. 


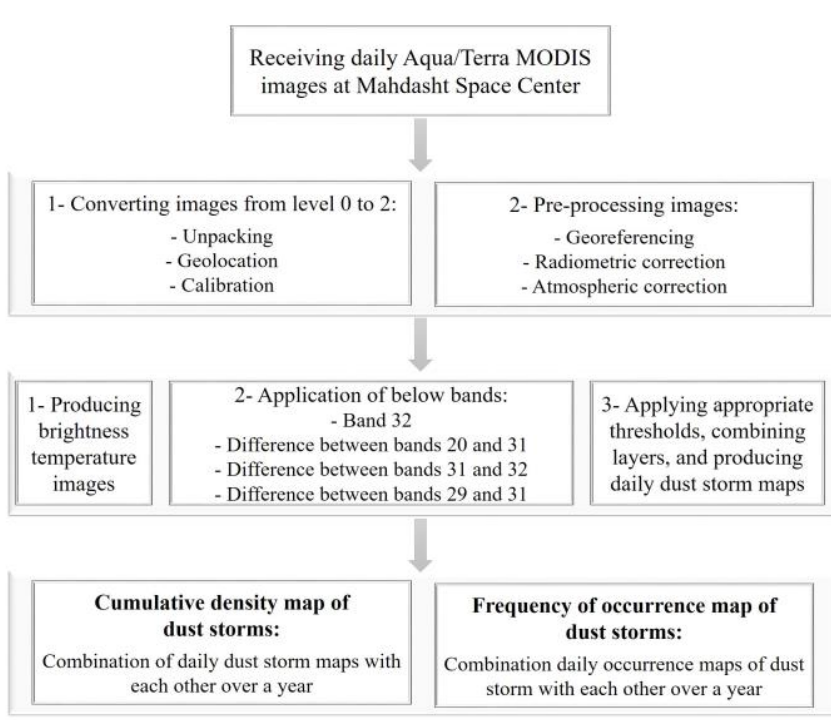

Figure 2. Flowchart of the proposed methodology

\section{RESULTS AND DISCUSSIONS}

After applying the algorithm on the daily MODIS images received from Terra and Aqua satellites at the Mahdasht Space Center of the Iranian Space Agency, 54 dust storms in 1396 and 70 dust storms in 1397 were detected on Iran (Table 1).

However, it should be noted that we cannot claim that all emerged dust storms in the country have been detected by us for the following reasons:

5- Terra and Aqua satellites pass over the country at a specific time, so it is probable that a dust storm be appeared on the country at the other hours of the day and be disappeared.

6- The spatial resolution of the data used were $1 \mathrm{~km}$, so it is probable that this low resolution be associated with the lack of accuracy in monitoring some local dust storms.

7- We have just focused on the dust storms that have been happened on Iran, nor whole the region.

8- On some days it was possible that some images had not been available at Mahdasht Space Center, so the probable dust may have been lost that day.

9- This study has been concentrated on the land, and many of the dust storms have not been monitored on the aquatic areas, especially the Persian Gulf.

From statistical point of view, Sistan and Baluchestan province in the southeast of the country with 29 , Khuzestan province in the southwest with 23 and Ilam province in the west with 16 dust storms have been encountered with the most monitored dust storms among the other provinces in 1396, respectively. While in 1397, Sistan and Baluchestan, Kerman and province Khorasan-South provinces which have respectively experienced 49, 42 and 30 monitored dust storms, are placed in the east and southeast parts of the country.

What is obvious in this stage without any further analysis, the number of dust storms at west and southwest areas have been reduced in 1397 in comparison to 1396. Conversely, in the eastern and southeast areas we have faced with an increase in the number of monitored dust storms in 1397.

\begin{tabular}{|c|c|c|c|c|}
\hline Province & Capital & $\begin{array}{l}\text { Area } \\
{\left[\mathrm{km}^{2}\right]}\end{array}$ & $\begin{array}{c}\text { Dust } \\
\text { monitored } \\
\text { in } 1396\end{array}$ & $\begin{array}{c}\text { Dust } \\
\text { monitored } \\
\text { in } 1396\end{array}$ \\
\hline Alborz & Karaj & 5,833 & 2 & 1 \\
\hline Ardabil & Ardabil & 17,800 & 1 & 0 \\
\hline $\begin{array}{l}\text { Azerbaijan, } \\
\text { East }\end{array}$ & Tabriz & 45,650 & 4 & 1 \\
\hline $\begin{array}{l}\text { Azerbaijan, } \\
\text { West }\end{array}$ & Urmia & 37,437 & 5 & 1 \\
\hline Bushehr & Bushehr & 22,743 & 3 & 10 \\
\hline $\begin{array}{c}\text { Chahar } \\
\text { Mahaal and } \\
\text { Bakhtiari }\end{array}$ & Shahrekord & 16,332 & 0 & 4 \\
\hline Fars & Shiraz & 122,608 & 1 & 5 \\
\hline Gilan & Rasht & 14,042 & 0 & 0 \\
\hline Golestan & Gorgan & 20,195 & 0 & 1 \\
\hline Hamadan & Hamadan & 19,368 & 0 & 1 \\
\hline Hormozgān & $\begin{array}{l}\text { Bandar } \\
\text { Abbas }\end{array}$ & 70,669 & 3 & 16 \\
\hline Ilam & Ilam & 20,133 & 16 & 9 \\
\hline Isfahan & Isfahan & 107,029 & 6 & 7 \\
\hline Kerman & Kerman & 183,285 & 7 & 42 \\
\hline $\begin{array}{c}\text { Kermansha } \\
h\end{array}$ & Kermanshah & 24,998 & 13 & 4 \\
\hline $\begin{array}{l}\text { Khorasan- } \\
\text { North }\end{array}$ & Bojnourd & 28,434 & 1 & 1 \\
\hline $\begin{array}{c}\text { Khorasan- } \\
\text { Razavi }\end{array}$ & Mashhad & 118,884 & 5 & 13 \\
\hline $\begin{array}{c}\text { Khorasan- } \\
\text { South }\end{array}$ & Birjand & 151,913 & 6 & 30 \\
\hline Khuzestan & Ahvaz & 64,055 & 23 & 13 \\
\hline $\begin{array}{c}\text { Kohgiluyeh } \\
\text { and Boyer- } \\
\text { Ahmad }\end{array}$ & Yasuj & 15,504 & 0 & 6 \\
\hline Kurdistan & Sanandaj & 29,137 & 13 & 1 \\
\hline Lorestan & Khorramabad & 28,294 & 0 & 1 \\
\hline Markazi & Arak & 29,130 & 1 & 2 \\
\hline $\begin{array}{c}\text { Mazandara } \\
n\end{array}$ & Sari & 23,701 & 0 & 0 \\
\hline Qazvin & Qazvin & 15,549 & 2 & 1 \\
\hline Qom & Qom & 11,526 & 5 & 2 \\
\hline Semnan & Semnan & 97,491 & 8 & 5 \\
\hline $\begin{array}{c}\text { Sistan and } \\
\text { Baluchestan }\end{array}$ & Zahedan & 180,726 & 29 & 49 \\
\hline Tehran & Tehran & 18,814 & 2 & 1 \\
\hline Yazd & Yazd & 129,285 & 5 & 12 \\
\hline Zanjan & Zanjan & 21,773 & 7 & 0 \\
\hline
\end{tabular}

Table 1. The number of dust monitored in different provinces of Iran during 1396 and 1397 Hijri Shamsi

\subsection{Analyzing cumulative density maps}

After the combination of all monitored dust storms in the years of 1396 and 1397, the cumulative density maps were produced for these two years (Figure 3 and Figure 4).

Respect to Figure 3, it is seen that cumulative density of dust has been high in Khuzestan province and some parts of Ilam province in 1396. Also, the cumulative density of dust is high in northeast of Sistan and Baluchestan province (Zabol city have been located in this area). Another considerable point is that although the number of monitored dust storms have been 8 for Semnan province, it is obvious that this province have been encountered with severe and dense dust storms. 


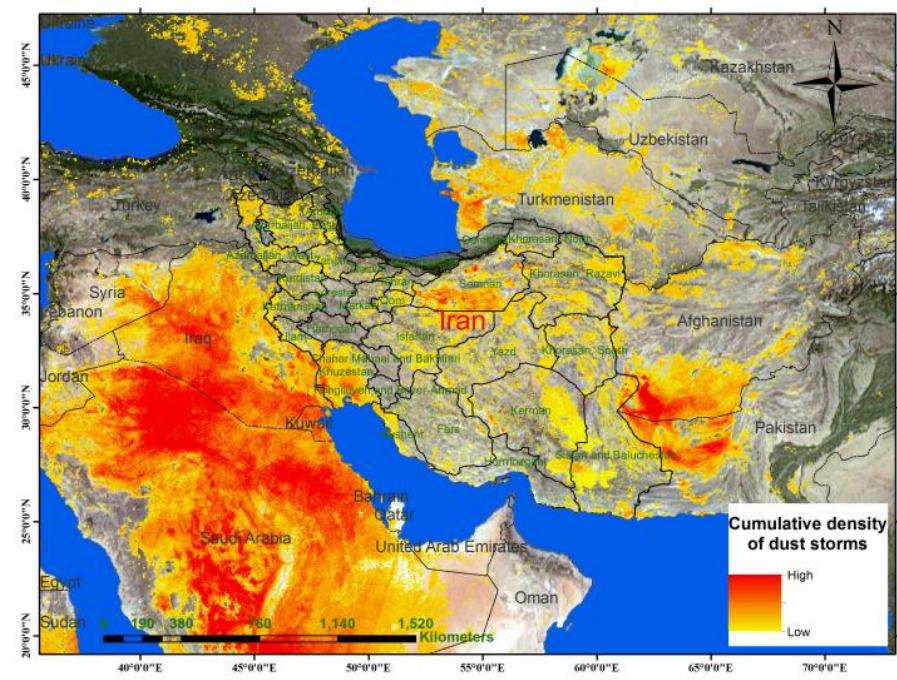

Figure 3. Cumulative density map of dust storms in 1396 Hijri Shamsi

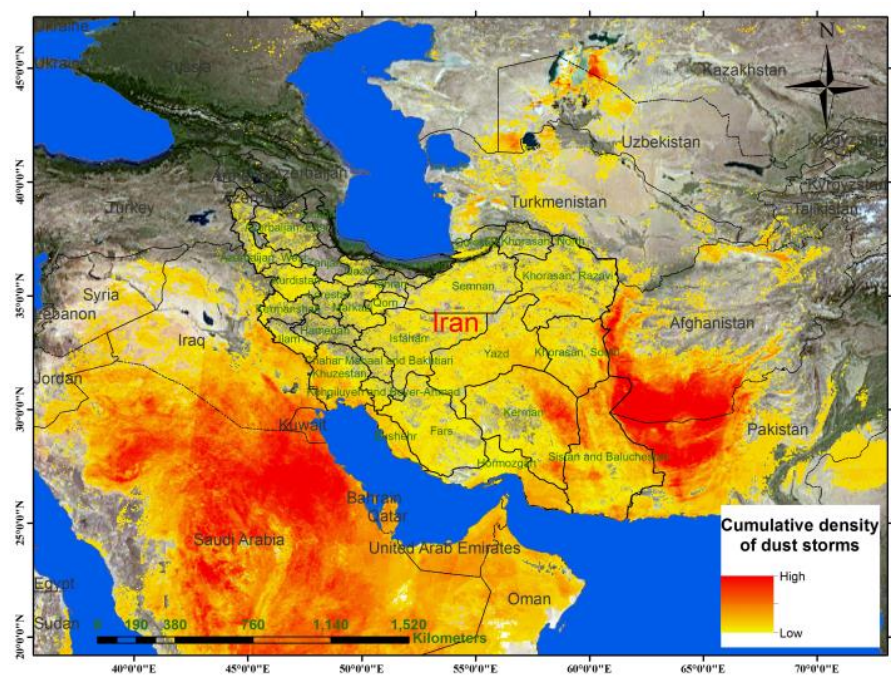

Figure 4. Cumulative density map of dust storms in 1397 Hijri Shamsi

Figure 4 shows that cumulative density of dust storms have been high in eastern parts of the country, especially northeast of

Sistan and Baluchestan province (around Zabol city), east of Kerman province and east of Khorasan-South province in 1397. Comparing Figures 3 and 4 leads us to some significant results:

1- In 1397, areas with high cumulative density of dust storms have been placed outside of Iran's borders. On the contrary, we are faced to such areas inside Iran in 1397, especially northeast of Sistan and Baluchestan province.

2- In 1397, more areas have experienced dust storms in comparison to 1396. This issue has been happened not only outside of Iran but also inside the country.

3- In the western countries of Iran (Iraq, Syria, Kuwait, Saudi Arabia, etc.), in 1396, it is observed that the cumulative density of dust storms is almost high. While in 1397, cumulative density of dust storms in the countries of Iraq and Syria has been reduced and the highest cumulative density of dust storms has been occurred in Saudi Arabia.

4- The previous raised issue can justify the reduction of cumulative density of dust storms in the west and southwest of the country in 1397.

\subsection{Analyzing frequency of occurrence maps density maps}

After preparing the daily occurrence maps of dust storm and combining them, the final maps of annual frequency of occurrence of dust storms were prepared in 1396 and 1397 (Figure 5 and Figure 6).

By reviewing the results of these two maps and comparing them to Figure 3 and Figure 4, it is evident that there is a great similarity between the number of occurrence of dust in different regions and the pattern of cumulative density of dust storms. To be more specific, it can be said that in areas where the cumulative density of dust was higher (as indicated in Section 4.1), the number of occurrence of dust was also higher.



Figure 5. Frequency of occurrence map of dust storms in 1396 Hijri Shamsi

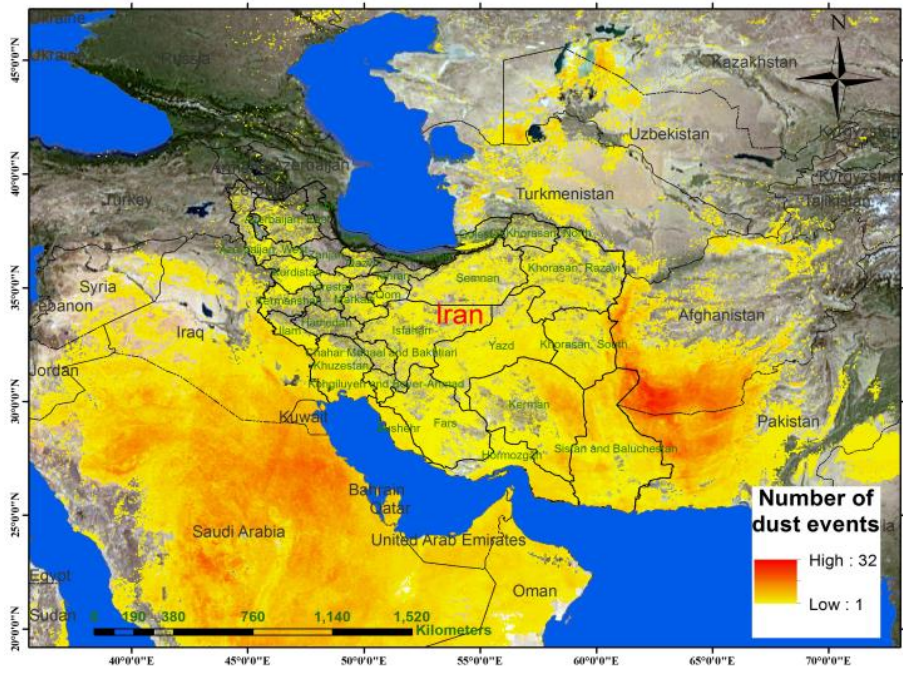

Figure 6. Frequency of occurrence map of dust storms in 1397 Hijri Shamsi 
In 1396, pixels which have been associated with high number of dust events are approximately located outside of Iran's borders. On the contrary, such pixels have been located in some eastern and southeastern parts of Iran in 1397. This issue requires special attention to these areas. Furthermore, in 1397, the number of repetitions of dust has also increased in such pixels. So that in 1396, the maximum number of dust per pixel was 27 . This number, however, has reached to 32 in 1397. Hence, critical areas in terms of dust storms have been faced to higher number of dust in 1397.

\section{CONCLUSION}

A continuous monitoring of dust storms and the combination of daily monitoring maps can help us to understand the patterns of density and repetition of dust storms. The initiative of this study is an annual monitoring of dust storms for two years and conducting relevant comparisons.

According to the results, the problem of dust storms in Iran have been shifted from the west and southwest of the country (including Khuzestan province) to the eastern and southeastern regions (especially the provinces of Sistan and Baluchestan and Kerman). Also, in 1397, more areas of the country have experienced dust storms in comparison to 1396. Another issue which deserves some words is that we are faced to areas with high cumulative density of dust storms and number of occurrence inside Iran in 1397, especially northeast of Sistan and Baluchestan province.

This study suggest that managers and decision makers must have more attention on eastern and southeastern areas of the country. To this end, serious agreements must be made between Iran and the neighboring countries in the east (Afghanistan and Pakistan) in order to carry out management and control activities to reduce dust storms and relative social, economic and health problems.

This study has been associated with some limitations which should be considered in future studies. Low spatial resolution, lack of monitoring dust storms on the aquatic area, low accuracy in desert areas during cold seasons and precise separation between cloud and dust.

\section{ACKNOWLEDGEMENTS}

We would like to express our sincere gratitude to Mr. Ali Sadeghi Naeini, Dr. Mostafa Esmaeili and Mr. Yousef Mousivand for their technical assistance and useful discussions.

\section{REFERENCES}

Alizadeh-Choobari, O., Zawar-Reza, P., Sturman, A., 2014. The "wind of 120 days" and dust storm activity over the Sistan Basin. Atmospheric Research, 143, 328-341.

Baddock, M.C., Bullard, J.E., Bryant, R.G., 2009. Dust source identification using MODIS: A comparison of techniques applied to the Lake Eyre Basin, Australia. Remote Sensing of Environment. 113(7), 1511-1528.

Bartlett, Kevin., 2004. Dust Storm Forecasting for Al Udeid AB, Qatar: An Empirical Analysis. Air Force Inst of Tech, Wright-Patterson Air Force Base, Air University, Ohio, Master's Thesis, 103 pages.

Givehchi, R., Arhami, M., Tajrishy, M., 2013. Contribution of the Middle Eastern dust source areas to PM10 levels in urban receptors: Case study of Tehran, Iran. Atmospheric Environment, 75, 287-295.

Heidarian, P., Azhdari, A., Joudaki, M., Darvishi Khatooni, J., Fathtabar Firoozjaei, S., 2018. Integrating Remote Sensing, GIS, and Sedimentology Techniques for Identifying Dust Storm Sources: A Case Study in Khuzestan, Iran. Journal of the Indian Society of Remote Sensing, 46(7), 1113-1124.

Kalpoma, K.A., Nagatani, I., Kawano, K., Kudoh, J.I., 2018. Development of a new dust index NDLI for Asian dust extraction system based on Aqua MODIS data and monitoring of trans-boundary Asian dust events in Japan. International Journal of Remote Sensing. 40(3), 1030-1047.

Karimi, N., Moridnejad, A., Golian, S., Vali Samani, J. M., Karimi, D., Javad, S., 2012. Comparison of dust source identification techniques over land in the Middle East region using MODIS data. Canadian Journal of Remote Sensing, 38(5), 586-599.

Klüser, L., Schepanski, K., 2009. Remote sensing of mineral dust over land with MSG infrared channels: a new Bitemporal Mineral Dust Index. Remote Sensing of Environment, 113 (9), 1853-1867.

Levy, R.C., Mattoo, S., Sawyer, V., Shi, Y., Colarco, P.R., Lyapustin, A.I., Wang, Y., Remer, L.A., 2018. Exploring systematic offsets between aerosol products from the two MODIS sensors. Atmospheric Measurement Techniques, 11(7), 4073-4092.

Maghrabi, A., Alharbi, B., Tapper, N., 2011. Impact of the March 2009 dust event in Saudi Arabia on aerosol optical properties, meteorological parameters, sky temperature and emissivity. Atmospheric Environment, 45(13), 2164-2173.

Miri, A., Ahmadi, H., Ghanbari, A., Moghaddamnia, A., 2007. Dust Storms Impacts on Air Pollution and Public Health under Hot and Dry Climate. International Journal of Energy and Environment, 1(2), 101-105.

Namdari, S., Valizade, K.K., Rasuly, A.A., Sari Sarraf, B., 2016. Spatio-temporal analysis of MODIS AOD over western part of Iran. Arabian Journal of Geosciences, Vol 9(191), 1-11.

Prachi, M.S., Pravin, K.D., 2014. Detection and Monitoring Of Two Dust Storm Events by Multispectral Modis Images. Journal of Environmental Research and Development, 8(4), 974-982.

Shao, Y., Dong, C.H., 2006. A review on East Asian dust storm climate, modelling and monitoring. Global and Planetary Change. 52, 1-22.

Taheri Shahraiyni, H., Karimi, Kh., 2014. Monitoring of dust storm and estimation of aerosol concentration in the Middle East using remotely sensed images. Arabian Journal of Geosciences, 8(4), 2095-2110.

Takemi, T., Seino, N., 2005. Dust storms and cyclone tracks over the arid regions in East Asia in spring. Journal of Geophysical Research: Atmospheres. 110(D18), 1-11. 